\title{
Safety of Conscious Sedation in Patients Undergoing Endoscopic Retrograde Cholangio Pancreatography
}

Lubna Kamani1, Abdul Latif Memon'1 and Adnan Anwar2

\begin{abstract}
Objective: To assess the safety of conscious sedation in patients undergoing endoscopic retrograde cholangio pancreaticography (ERCP).

Study Design: An observational study.

Place and Duration of Study: Department of Gastroenterology, Liaquat National Hospital, Karachi, from April 2010 to April 2015.

Methodology: All patients underwent ERCP procedure under midazolam and/or nalbuphine were included. Safety was assessed by monitoring the hemodynamics and complications during procedure till discharge from hospital. SPSS version 20 was used for descriptive analysis.

Results: A total of 550 procedures were enrolled for the study. The mean age of the patients was $50.85 \pm 15.66$ years. There were $197(35.8 \%)$ males. Out of 550 procedures, only $2(0.4 \%)$ reported complications. The study reports a success rate of $531(96.5 \%)$ procedures who underwent ERCP with conscious sedation. Only 19 (3.5\%) cases could not be completed successfully under conscious sedation and were converted to general aneasthesia.

Conclusion: The present study shows that ERCP technique is safe under conscious sedation as it delivers balanced tranquillity.
\end{abstract}

Key Words: Conscious sedation, General aneasthesia, Endoscopic retrograde cholangiopancreatography, Biliary disease.

\section{INTRODUCTION}

Endoscopic retrograde cholangio pancreatography (ERCP) is a challenging and lifesaving procedure to treat hepatopancreaticobiliary disorders. The pain and discomfort from the procedure may occasionally cause vigorous body motion, preventing safe examination. 1 One significant factor to counter pain and discomfort is the use of intravenous sedation. ${ }^{2}$ Sedation is a technique by which depression of consciousness is achieved to alleviate the pain and discomfort associated with therapeutic procedures. ${ }^{3}$ One of the key factors determining the success of the procedure is the administration of either moderate or deep sedation. 4 Currently, sedation is mainly performed using a benzodiazepine such as midazolam and a semi synthetic opioid like, nalbuphine hydrochloride; these have been adopted to alleviate the pain experienced during ERCP. Therefore, the use of sedative agent to a patient remains a topic of debate. Many studies favour usage of conscious sedation, while other studies suggest that since propofol has rapid onset and off-set

1 Department of Gastroenterology, Liaquat National Hospital, Karachi, Pakistan

2 Department of Physiology, Altibri Medical College, Karachi, Pakistan

Correspondence: Dr. Lubna Kamani, Department of Gastroenterology, Liaquat National Hospital, Karachi, Pakistan

E-mail: lkamani@yahoo.com

Received: January 29, 2018; Accepted: July 12, 2018 of sedation with quick recovery time, it should be preferred. According to a recommendation from American Society of Gastrointestinal Endoscopy (ASGE), deep sedation should only be preferred if the procedure is complex and time consuming. ${ }^{5}$ European Society of Gastrointestinal Endoscopy (ESGE) has published guidelines to provide general physicians with a comprehensive framework for propofol sedation during digestive tract endoscopy, including ERCP. 6

Many gastroenterologist and anesthesiologists suggested that patients with less severe pathologies should be given conscious sedation that can be administered by the trained staff or by the physician himself to reduce cost of anesthesiologist-administered sedation. ${ }^{7}$ Many studies have also recommended propofol, administered by nurses or a gastroenterologist, as a safe and effective method to reduce the cost of anesthesiologistadministered sedation.8-10 Endoscopy units should assure to practise guidelines regarding procedurerelated sedation, including certification, training of staff, maintenance of rescue equipment, formation of suitable emergency protocols, and quality assurance programme. ${ }^{3}$

There is not much local data available to assess the safety of conscious sedation during ERCP procedure. Hence, the objective of this study was to determine the safety and success rate of ERCP under conscious sedation.

\section{METHODOLOGY}

This was an observational study, conducted from April 2010 to April 2015, in the Department of Gastroenterology, Liaquat National Hospital, Karachi, after approval of 
Hospital Ethics Committee. Informed consent for ERCP under conscious sedation was taken. The inclusion criteria were all patients who underwent ERCP under influence of conscious sedation including weight-based midazolam and/or nalbuphine. Patients with severe cardio respiratory compromise (ASA IV and V) were excluded and not included in analyses as these patients require general aneasthesia.

Data were collected from patients' medical records retrospectively. The baseline demographics of each patient was recorded. Safety was assessed by monitoring the sedation related hemodynamics.

SPSS version 20.0 IBM, Chicago, USA, was used for data entry and analysis. Mean and standard deviation were calculated for quantitative variables. Frequencies

Table I: Basic demographics of patients.

\begin{tabular}{|c|c|}
\hline Variables $(n=550)$ & Mean \pm SD / Frequency $(\%)$ \\
\hline Age (years) & $50.85 \pm 15.66$ \\
\hline \multicolumn{2}{|l|}{ Gender } \\
\hline Male & $197(35.8 \%)$ \\
\hline Female & $353(64.2 \%)$ \\
\hline \multicolumn{2}{|l|}{ ASA } \\
\hline I & $268(48.7 \%)$ \\
\hline II & $206(37.4 \%)$ \\
\hline III & $76(13.8 \%)$ \\
\hline Duration of hospital stay (days) & $2.42 \pm 1.41$ \\
\hline \multicolumn{2}{|l|}{ Comorbid } \\
\hline Hypertension & $140(25.5 \%)$ \\
\hline Diabetes & $62(11.3 \%)$ \\
\hline Ischemic heart & $126(22.9 \%)$ \\
\hline Others & $28(5.1 \%)$ \\
\hline Nil & $189(34.4 \%)$ \\
\hline \multicolumn{2}{|l|}{ Associated symptoms } \\
\hline \multicolumn{2}{|l|}{ Pain } \\
\hline Generalized abdominal & $209(38 \%)$ \\
\hline Right hypochondrial & $11(2 \%)$ \\
\hline Epigastric & $6(1.1 \%)$ \\
\hline Fever & $85(15.5 \%)$ \\
\hline Jaundice & $16(2.9 \%)$ \\
\hline Nausea & $12(2.2 \%)$ \\
\hline Vomiting & $61(11.1 \%)$ \\
\hline Chills & $4(0.7 \%)$ \\
\hline Itching & $2(0.4 \%)$ \\
\hline Weight loss & $2(0.4 \%)$ \\
\hline Anorexia & $1(0.2 \%)$ \\
\hline \multicolumn{2}{|l|}{ Diagnosis } \\
\hline Choledocholithiasis & $349(63.4 \%)$ \\
\hline Biliary stricture & $117(21.3 \%)$ \\
\hline Biliary Leak & $23(4.2 \%)$ \\
\hline Cystic duct stone & $6(1.1 \%)$ \\
\hline Common bile duct stone and stricture & $4(0.7 \%)$ \\
\hline Common bile duct worms & $1(0.2 \%)$ \\
\hline Dilated common bile duct & $14(2.5 \%)$ \\
\hline Periamullary growth & $10(1.8 \%)$ \\
\hline Pancreatic duct stone & $2(0.4 \%)$ \\
\hline Pancreatic duct leak & $1(0.2 \%)$ \\
\hline Pancreatic duct disruption & $2(0.4 \%)$ \\
\hline Normal examination & $21(3.8 \%)$ \\
\hline
\end{tabular}

and percentages were calculated for qualitative variables like gender, presence or absence of obstructive jaundice, diagnosis.

\section{RESULTS}

During the study, a total of 550 patients underwent ERCP procedure, performed to either diagnose or treat hepatopancreaticobiliary disorders. The mean age of patients was found to be $50.85 \pm 15.66$ years. There were 197 (35.8\%) male patients. Baseline demographics, presenting complaints and indication of ERCP, are outlined in Table I.

Mean dosages of injection midazolam and nalbuphine were $6 \pm 2 \mathrm{mg}, 7 \pm 3 \mathrm{mg}$, respectively. In 19 patients $(3.5 \%)$, the procedure was converted from conscious sedation to general anesthesia because of agitation and restlessness despite maximum sedation (weightbased). Out of 550 procedures, only $2(0.4 \%)$ reported complication of minor ampullary bleeding during sphinterotomy, which was managed endoscopically with injection of diluted adrenaline, none of the patients had post-ERCP severe pancreatitis or perforation. Details of therapeutics performed during procedure are shown in Table II. The study reports a success rate of $531(96.5 \%)$ under conscious sedation. None of the patient had cardiopulmonary arrest or required any emergency intubation for airway maintenance. Patients were monitored for oxygen saturation and heart rate contionously, while blood pressure monitoring was done every five minutes during procedure, and 60 minutes post-procedure in recovery room.

\section{DISCUSSION}

This study determined that conscious sedation administered during ERCP procedure is not only safe but also feasible for gastroenterologists with insignificant incidence of procedure-related complications. Our study reported a success rate of $531(96.5 \%)$ procedures. Our interpretations confirmed the findings of the previous

Table II: Therapeutic during ERCP.

\begin{tabular}{lrr}
\hline Variables & $\mathrm{n}$ & $\%$ \\
\hline Sphincteroplasty & 36 & 6.5 \\
Yes & 514 & 93.3 \\
$\quad$ No & 21 & \\
\hline Double wire technique & 3.9 \\
$\quad$ Yes & 529 & 96.1 \\
$\quad$ No & & \\
Balloon sweep & 365 & 66.3 \\
Yes & 195 & 35.5 \\
$\quad$ No & & \\
\hline Outcomes & 531 & 96.5 \\
Success & 19 & 3.5 \\
$\quad$ Failure & & \\
Stent & 166 & 30.2 \\
Plastic & 61 & 11.1 \\
Metallic & 323 & 58.7 \\
$\quad$ Nil & &
\end{tabular}


studies.11,12 ERCP is an invasive and a time-consuming procedure and can cause discomfort to patients. ${ }^{13}$ Two of the most commonly encountered complications of this procedure are abdominal pain and hemorrhage. Hemorrhage is a complication more frequently associated with sphincterotomy rather than diagnostic ERCP. ${ }^{14}$ This study is also in accordance with other studies that reported similar findings. However, in the present study, frequency of hemorrhage was lower with only two reported cases. ${ }^{14-16}$

Risk factors for hemorrhage identified in multivariate analysis in a study included presence of a coagulopathy at the time of the procedure, administration of anticoagulants within 48-72 hours of the ERCP, the presence of acute cholangitis or papillary stenosis, etc. ${ }^{14-16}$ Hence, we can exclude hemorrhage as one of the complications associated with the administration of conscious sedation as it is common for patients to have procedure-related complications irrespective of the type of sedation or anesthesia used.

Morse et al. recommended administration of moderate sedation during the gastrointestinal endoscopy because it provides sufficient relief from pain with minimum adverse effects than deep sedation. ${ }^{17}$ In fact, many supporting studies have concluded that administration of conscious sedation by nurses or a gastroenterologist is a safe and effective method to reduce the cost of anesthesiologist-administered sedation. $8-10$

In contrast, few studies have concluded that gastroenterologist-directed sedation has similar efficacy and complication rate as those with anesthesiologist-directed sedation. 17,18 In disagreement to the present study, some researchers have reported high physician satisfaction and more successful procedure rate under anesthesia. The major weakness of these studies is that it has not been controlled or lack blinding, which may contribute to research bias. ${ }^{19}$ The qualitative approach of this study has assured that we have assessed the range of safety of the ERCP procedure under conscious sedation.

\section{CONCLUSION}

It was observed that ERCP was safe under conscious sedation as it delivered balanced tranquillity.

\section{REFERENCES}

1. Minami T, Sasaki T, Serikawa M, Ishigaki T, Ishii $Y$, Mouri $T$, et al. Safety and effectiveness of propofol sedation during endoscopic retrograde cholangiopancreatography. J Anesth Clin Res 2015; 6:513.

2. Amornyotin S, Leelakusolvong $S$, Chalayonnawin W, Kongphlay S. Age-dependent safety analysis of propofolbased deep sedation for ERCP and EUS procedures at an endoscopy training center in a developing country. Clin Exp Gastroenterol 2012; 5:123-8.

3. Cohen LB, Delegge MH, Aisenberg J. AGA Institute review of endoscopic sedation. Gastroenterology 2007; 133:675-701.
4. Raymondos K, Panning B, Bachem I, Manns MP, Piepenbrock S, Meier PN. Evaluation of endoscopic retrograde cholangiopancreatography under conscious sedation and general anesthesia. Endoscopy 2002; 34:721-6.

5. Lichtenstein DR, Jagannath $S$, Baron $T H$, Anderson MA, Banerjee S, Dominitz JA, et al. Sedation and anesthesia in GI endoscopy. Gastrointest Endosc 2008; 68:815-26.

6. Dumonceau J, Riphaus A, Aparicio JR, Beilenhoff U, Knape JT, Ortmann $\mathrm{M}$, et al. European society of gastrointestinal endoscopy, European society of gastroenterology and endoscopy nurses and associates and the European society of anaesthesiology guideline: Non-anesthesiologist administration of propofol for GI endoscopy. Endoscopy 2010; 42:960-74.

7. Cohen LB, Ladas SD, Vargo JJ, Paspatis GA, Bjorkman DJ, Van der Linden $P$, et al. Axon AT, Sedation in digestive endoscopy: the Athens international position statements. Aliment Pharmacol Ther 2010; 32:425-42.

8. Vargo, John J, Lawrence B, Cohen, Douglas K, Rex, et al. Position statement: Nonanesthesiologist administration of propofol for GI endoscopy. Gastrointest Endoscop 2009; 70:1053-9.

9. Yusoff IF, Raymond G, Sahai AV. Endoscopist administered propofol for upper-GI EUS is safe and effective: a prospective study in 500 patients. Gastrointest Endosc 2004; 60:356-60.

10. Fanti $L$, Testoni PA. Sedation and analgesia in gastrointestinal endoscopy: What's new? World J Gastroenterol 2010; 16:2451.

11. Amornyotin S, Srikureja W, Pausawasdi N, Prakanrattana U, Kachintorn U. Intravenous sedation for gastrointestinal endoscopy in very elderly patients of Thailand. Asian Biomed 2011; 5:485-91.

12. Amornyotin S, Kachintorn U, Chalayonnavin W, Kongphlay S. Propofol-based deep sedation for endoscopic retrograde cholangiopancreatography procedure in sick elderly patients in a developing country. Ther Clin Risk Manag 2011; 7:251-5.

13. Amornyotin S, Phasurin T, Wongnuch P. Pain score within twenty-four hours post-endoscopic retrograde cholangiopancreatography: a comparison between diagnostic and therapeutic procedures. Gastroenterol Insights 2009; 1:20-3.

14. Freeman ML, Nelson DB, Sherman S, Haber GB, Herman ME, Dorsher PT, et al. Complications of endoscopic biliary sphincterotomy. N Engl J Med 1996; 335:909-18.

15. Loperfido S, Angelini G, Benedetti G, Chilovi F, Costan F, De Berardinis $F$, et al. Major early complications from diagnostic and therapeutic ERCP: a prospective multicenter study. Gastrointest Endosc 1998; 48:1-10.

16. Masci E, Toti G, Mariani A, Curioni S, Lomazzi A, Dinelli M, et al. Complications of diagnostic and therapeutic ERCP: A prospective multicenter study. Am J Gastroenterol 2001; 96:417-23.

17. Morse J, Bamias G. Ability to reverse deeper levels of unintended sedation. Digestion 2010; 82:94-6.

18. Mehta PP, Vargo JJ, Dumot JA, Parsi MA, Lopez R, Zuccaro G. Does anesthesiologist-directed sedation for ERCP improve deep cannulation and complication rates? Dig Dis Sci 2011; 56:2185-90.

19. Berzin TM, Sanaka S, Barnett SR, Sundar E, Sepe PS, Jakubowski $\mathrm{M}$, et al. A prospective assessment of sedationrelated adverse events and patient and endoscopist satisfaction in ERCP with anesthesiologist-administered sedation. Gastrointest Endosc 2011; 73:710-7. 